\title{
Diverse regulatory manners of human telomerase reverse transcriptase
}

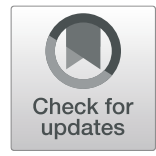

\author{
Meng-Meng Jie ${ }^{1 \dagger}$, Xing Chang ${ }^{1 \dagger}$, Shuo Zeng ${ }^{1 \dagger}$, Cheng Liu', Guo-Bin Liao', Ya-Ran Wu', Chun-Hua Liu², \\ Chang-Jiang $\mathrm{Hu}^{1}$, Shi-Ming Yang ${ }^{1 *}$ and Xin-Zhe $\mathrm{Li}^{\mathrm{i}^{*}}$
}

\begin{abstract}
Human telomerase reverse transcriptase (hTERT) is the core subunit of human telomerase and plays important roles in human cancers. Aberrant expression of hTERT is closely associated with tumorigenesis, cancer cell stemness maintaining, cell proliferation, apoptosis inhibition, senescence evasion and metastasis. The molecular basis of hTERT regulation is highly complicated and consists of various layers. A deep and full-scale comprehension of the regulatory mechanisms of hTERT is pivotal in understanding the pathogenesis and searching for therapeutic approaches. In this review, we summarize the recent advances regarding the diverse regulatory mechanisms of hTERT, including the transcriptional (promoter mutation, promoter region methylation and histone acetylation), post-transcriptional (mRNA alternative splicing and non-coding RNAs) and post-translational levels (phosphorylation and ubiquitination), which may provide novel perspectives for further translational diagnosis or therapeutic strategies targeting hTERT.
\end{abstract}

Keywords: hTERT, Regulation, Transcription, Post-transcription, Post-translational modification

\section{Background}

Telomeres are located at the ends of chromosomes and their major functions are to maintain chromosomal integrity and genome stability [1]. Telomerase is a complex ribonucleoprotein and an essential reverse transcriptase which promotes the capping of eukaryotic telomere ends [2,3]. The activity of telomerase is absent in most somatic tissues whereas it is commonly present in germ cells and some stem cells [4-6]. Dysregulation of telomerase results in its activation in approximately $90 \%$ of human cancers [7]. Importantly, cancer cells have acquired the ability to overcome replicative senescence and enhance growth ability via maintaining telomere length and activity. The differences between normal and cancer cells make telomerase an attractive cancer biomarker in clinical practice $[8,9]$. The core human telomerase comprises of two essential components: the template RNA subunit, human telomerase RNA (hTERC), and the catalytic protein subunit, human

\footnotetext{
* Correspondence: shimingyang@yahoo.com; lixinzhe73@126.com

${ }^{\dagger}$ Meng-Meng Jie, Xing Chang and Shuo Zeng contributed equally to this work.

${ }^{1}$ Department of Gastroenterology, Xinqiao Hospital, Third Military Medical University (Army Medical University), Chongqing 400037, China Full list of author information is available at the end of the article
}

telomerase reverse transcriptase (hTERT) [10, 11]. The expression and function of hTERT are crucial determinants of telomerase activity, which are strictly controlled by various molecule events in multiple layers. In this review, we summarize the diverse regulatory mechanisms of hTERT.

\section{Regulation of hTERT at transcriptional levels}

Numerous researches have been performed to investigate the regulation of hTERT transcription through direct binding of transcription factors to the wild-type (WT) hTERT promoter. Canonical positive regulators include the multifunctional transcription factors c-MYC, NF-kB, and STAT3. c-MYC dimerizes with its partner MAX and binds to the E-box sequences on the hTERT core promoter region, which activates the transcription of hTERT [12-14]. Besides, c-MYC could cooperate with specificity protein 1 (SP1) to elevate hTERT transcription through their respective binding sites on the hTERT promoter region $[15,16]$. In addition, a variety of factors regulate hTERT transcription by modulating c-MYC. For instance, p300 activates hTERT gene expression by interacting with and stabilizing c-MYC [17]. Sirtuin 1 (SIRT1) increases hTERT expression via upregulating FOXO3a-mediated activation of c-MYC

(c) The Author(s). 2019 Open Access This article is distributed under the terms of the Creative Commons Attribution 4.0 International License (http://creativecommons.org/licenses/by/4.0/), which permits unrestricted use, distribution, and 
expression in human umbilical cord fibroblast cells [18]. Aurora-A kinase promotes c-MYC expression thereby increasing hTERT expression [19]. As for NF-kB, it regulates hTERT gene transcription by direct binding to the proximal promoter region of hTERT [20-22] or by indirectly modulating the upstream regulators of hTERT [23, 24]. STAT3 also shows an important regulatory role in hTERT expression in various cancer cell lines [25, 26]. In addition to the positive regulators, the negative regulators of hTERT include E2F1 [27, 28] and MAD1 [29-31].

Interestingly, several transcription factors play dual roles in hTERT transcription. One representative is SP1. It has been reported that SP1 can activate hTERT expression by binding to five GC-box motifs at the hTERT promoter region in telomerase-positive cells [15, 32, 33]. Besides, SP1 could cooperate with c-MYC to bind to the promoter region of hTERT thereby upregulating hTERT $[15,16]$. On the contrary, in telomerase-negative somatic cells, suppression of hTERT is due to the binding of SP1 to the proximal promoter region and recruitment of histone deacetylase (HDAC) proteins to the binding motifs $[34,35]$. Histone deacetylation results in the silencing of hTERT transcription. Other factors that play duel effects on hTERT transcription include activator protein 1 (AP-1) [36, 37] and hypoxia-inducible factor 2-alpha (HIF2 $\alpha)$ [38].

In addition to the common transcriptional regulation manners described above, genetic mutations and/or epigenetic modifications (methylation and acetylation) provide other regulatory modes to precisely alter the transcription of hTERT.

\section{Promoter mutations}

\section{Regulation and function}

hTERT promoter mutations are frequently recurring events in many cancer types [39], including hepatocellular carcinoma (HCC), glioblastoma multiforme (GBM), thyroid carcinoma, urothelial cancer and melanoma [40-47]. However, they are rarely detected in lung, prostate, breast, gastrointestinal and kidney cancers and hematological malignancies [41, 47-49]. To date, two point mutations seem to be the most important. The $\mathrm{C}>\mathrm{T}$ mutation takes place at the nucleotide residue 146 or -124 of the proximal promoter region upstream from the ATG start site in a mutually exclusive manner, which is termed $-146 \mathrm{C}>\mathrm{T}$ or $-124 \mathrm{C}>\mathrm{T}$, respectively. These two somatic mutations give rise to the de novo generation of the E-twenty-six (ETS) family transcription factors consensus binding motifs $[44,50,51]$. The siRNA screening and subsequent verification experiments reveal that among the 13 ETS transcription factors, GABPA is the most positively related to the hTERT expression in hTERT promoter mutant (hTERT ${ }^{\text {Mut }}$ ) GBM cell lines [52]. Besides, bioinformatics prediction and subsequent experimental validation suggest that GABPA is specifically recruited to the mutation site of the hTERT promoter region during telomerase reactivation. GABPA knocking down dramatically decreases the activity of the mutant hTERT promoter without affecting that of the WT promoter, indicating that GABPA is the hTERT-regulating ETS factor that acts in a mutation-specific manner [52]. In addition, in multiple cancer cell lines that carry heterozygous mutant hTERT promoters, the mutant promoters display the active chromatin marker H3K4me2/3 and recruit the ETS family transcription factor GABPA/B1. On the contrary, the WT hTERT allele retains the epigenetic suppressive marker H3K27me3. These results suggest that only the mutant promoters are transcriptionally active and that one single base pair mutation can result in a dramatic epigenetic switch [53]. Interestingly, the selective upregulation of GABPB1 (but not of GABPA or GABPB2) in hTERT $^{\text {Mut }}$ HCC cells could specifically enhance the levels of GABPA-bound genes (such as hTERT) other than other ETS transcription factor-regulated genes [52, 53]. Notably, some reports suggested that the $-146 \mathrm{C}>\mathrm{T}$ and -124 $\mathrm{C}>\mathrm{T}$ mutant hTERT promoters function differently and that they take effect depending on the context $[54,55]$. In the background of the $-146 \mathrm{C}>\mathrm{T}$ mutation, a novel ETS binding motif promotes the dimerization and cooperative binding of ETS1 and p52 to the hTERT promoter region. However, this phenomenon is present in neither WT nor - 124 C > T hTERT promoters. Therefore, stabilization of the ETS-p52 complex on the $-146 \mathrm{C}>\mathrm{T}$ mutant hTERT promoter enhances hTERT expression in the context of non-canonical NF- $\mathrm{kB}$ signaling [55]. In addition to the canonical $-146 \mathrm{C}>\mathrm{T}$ and $-124 \mathrm{C}>\mathrm{T}$ mutations, two $\mathrm{CC}>$ TT tandem mutations (-124/-125 bp and $-138 /-139$ bp) also produce the ETS transcription factor binding motifs, which probably heighten the transcription of hTERT $[56,57]$. In conclusion, the ETS family transcription factors cooperate with the mutant hTERT promoters to enhance hTERT expression.

The hTERT promoter mutations also frequently accompany with the mutations of other oncogenic genes or tumor suppressors. For example, the co-occurrence of mutant hTERT promoter and TP53/RB1 mutations are found in bladder cancer (BC), suggesting a cooperative contribution to the $\mathrm{BC}$ progression [58]. Furthermore, hTERT promoter mutations are also closely associated with FGFR3 mutations in BC [59], or with BRAF/NRAS mutations in melanoma or papillary thyroid carcinoma (PTC) [60, 61].

\section{Clinical significances}

hTERT promoter mutations are tightly correlated with enhanced hTERT transcription and increased telomerase activity in tumors, which indicates that hTERT promoter mutations may be an essential mechanism of telomerase 
reactivation in cancers [45, 62-64]. In addition, hTERT promoter mutations are present in malignant tumors whereas they are absent in normal tissues, and hTERT promoter mutations are associated with poor survival or early diagnosis in various cancer types. The most representative cancer types are urothelial cancers because they harbor high frequencies of hTERT promoter mutations and can predict distant metastasis [46, 65-67]. Wang and colleagues detect the levels of the mutant hTERT promoter in urinary DNA derived from BC and renal pelvic cancer (RPC) patients before and after surgery, respectively. Their results show that the mutant hTERT promoter can serve as a urinary biomarker for diagnosis and recurrence surveillance [67]. Among BC patients, the hTERT promoter mutations are the most clinically related somatic lesions. Patients with hTERT promoter mutations showed poor prognosis in the absence of the allele of the rs2853669 polymorphism. Moreover, the mutations without this variant allele were highly correlated with the recurrence in patients with Tis, Ta, and T1 tumors [45].

When examining thyroid nodule specimens prior to operation, it is found that all 9 specimens from thyroid cancer patients contain mutant hTERT whereas no hTERT promoter mutations are detected in 179 benign specimens, which reveals a 100\% diagnostic specificity [68]. In addition, PTCs that concurrently harbor $\mathrm{BRAF}^{\mathrm{V} 600 \mathrm{E}}$ and hTERT promoter mutations $(-124 \mathrm{C}>$ $\mathrm{T})$ are more aggressive compared to either mutation alone, which defined a new genetic background with the worst clinicopathologic prognosis. Therefore, combinations using BRAF and hTERT promoter mutations may redirect the risk classifications of PTC $[69,70]$.
Among glioma patients, the relationship between hTERT promoter mutations and prognosis is relatively complicated, and additional factors such as tumor grade, and other genetic mutations can also make a difference. For example, the presence of $-146 \mathrm{C}>\mathrm{T}$ and $-124 \mathrm{C}>\mathrm{T}$ mutations is bound up with a shorter overall survival (OS) in high-grade glioma patients. However, OS was longer for low-grade glioma patients with these mutations [71]. In addition, patients with grade II and III gliomas who harbor only hTERT promoter mutations have a relatively poorer OS, in contrast, patients harboring both TERT and IDH mutations show good outcomes [72-74]. Nault et al. found that hTERT promoter mutation is the earliest as well as the most frequent genetic alteration in early HCC. Therefore, hTERT promoter mutation may be a novel biomarker predicting transformation of premalignant lesions into HCC [75]. Among melanoma patients, the co-existence of hTERT promoter and BRAF/NRAS mutations were related to 2-fold reduced disease-free and 5-fold reduced melanoma-specific survival [76]. Even in clear cell renal cell cancer (ccRCC) that harbored a relatively low frequency of hTERT promoter mutations compared to other cancers, Hosen et al. shows that ccRCC patients with hTERT promoter mutations in the absence of the rs2853669 polymorphism had the worst disease-specific survival [77]. Taken together, the mutant hTERT promoters may facilitate the malignant phenotypes of cancers and predict poor prognosis by upregulating the expression of hTERT. Transcription factors and promoter mutations that regulate the expression of hTERT are shown in Fig. 1.

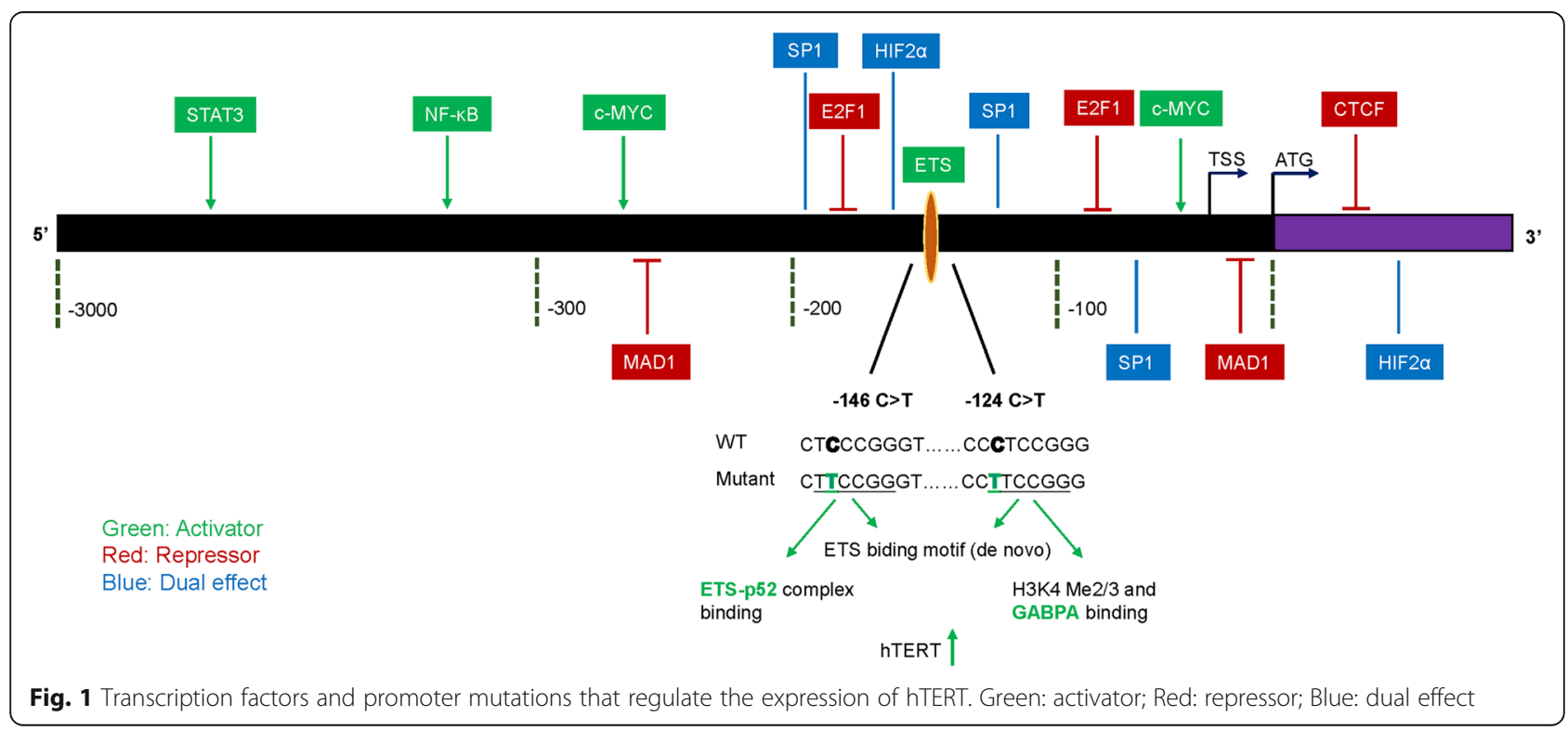




\section{Promoter region methylation}

As mentioned above, tumor types such as breast cancer and prostate cancer do not display high frequency of hTERT promoter mutations. Thus, there may be other regulatory mechanisms of hTERT transcription. Therefore, epigenetic mechanisms such as promoter region methylation or histone acetylation are likely to play effects. Traditionally, methylation of gene promoter region is often associated with gene expression silencing. Methylation of the first E-box CpG site ( -165 to -160 bp) of hTERT promoter region and/or histone H3K9 hinders the binding of c-MYC and consequently decreases hTERT expression in HCC. When histone H3K9 is acetylated and the promoter region of hTERT is not methylated, c-MYC could enhance hTERT expression [78]. Besides, the hTERT promoter region is unmethylated in undifferentiated embryonic human teratocarcinoma (HT) cells. Retinoic acid (RA) treatment increases hTERT promoter region methylation and suppresses its expression. In addition, treatment with Trichostatin A (TSA) reactivates hTERT in only very early differentiating HT cells. In late differentiating cells, treatment with 5-AZA, but not TSA, upregulates the hTERT transcription, suggesting that histone deacetylation correlates with early hTERT expression inhibition and that hTERT promoter region methylation may maintain this silencing effect [79].

On the contrary, various studies have demonstrated that methylation within the regulatory element of the hTERT promoter region can enhance rather than weaken the expression of hTERT $[80,81]$, whereas demethylation decreases hTERT expression [82-84]. An example is the regulation of the hTERT promoter region by the repressive factor CTCF. Renaud et al. reveals that methylation of the hTERT promoter region plays a dual role inside and outside the CTCF-binding regions [83]. On the one hand, CTCF binds to the unmethylated first exon (+ 4 to $+39 \mathrm{bp})$ of hTERT thus repressing its transcription. Nevertheless, CTCF does not bind to the methylated first exon of hTERT. Besides, upon treatment with the demethylating agent 5-AZA, CTCF could interact with the hTERT promoter region and downregulate its mRNA level. These results suggest that hTERT promoter region methylation is essential for its transcription $[83,85,86]$. On the other hand, total methylation of the hTERT promoter region leads to full transcriptional repression, and the methylation cassette assay reveals that selective demethylation of a specific $110 \mathrm{bp}$ sequence (183 to $-74 \mathrm{bp}$ ) within the core promoter region of hTERT significantly increases its transcription [83]. Thus, hypermethylation of most $\mathrm{CpG}$ islands restricts the binding of repressive factors and hypomethylation of specific regions allows the binding of activating factors. This dynamic equilibrium elaborately regulates hTERT promoter activation, which finally affects hTERT transcription. Another hTERT repressor, Wilms tumor protein (WT1), shows a methylation-sensitive binding manner to DNA sequences [87]. When its binding sequence is methylated, the binding affinity of WT1 is reduced. Therefore, methylation of the hTERT promoter region within the WT1 binding site ( -358 to $-349 \mathrm{bp}$ ) derepresses hTERT transcription [79]. Intriguingly, DNA methylation analysis shows that the hTERT promoter region around the transcriptional starting site (TSS) ($200 /-150$ to $+150 \mathrm{bp}$ ) is hypomethylated and associated with active chromatin marks, while the promoter region upstream of the TSS ( -650 to $-200 /-150 \mathrm{bp}$ ) is significantly hypermethylated [88, 89].

Several bioactive dietary, such as EGCG [90], Sulforaphane (SFN) [91] or Genistein [92], components display antitumor effects through regulating the methylation manner of the hTERT promoter region. EGCG weakens methylation of the hTERT promoter region in a time-dependent manner in MCF-7 breast cancer cells. Besides, EGCG induces demethylation at the putative E2F1 binding sites within the hTERT promoter region and increases the binding capacity of E2F1 at these sites, which may be a proposed mechanism for downregulation of hTERT by EGCG [90]. SFN treatment downregulates hTERT and reduces DNA methyltransferase 1 (DNMT1) and DNA methyltransferase 3a (DNMT3a) in human breast cancer cells. DNMTs reduction leads to site-specific CpG demethylation primarily in the first exon of the hTERT gene, which facilitates the association of CTCF with hTERT [91]. In addition, Genistein or EGCG inhibits transcription of hTERT via suppressing DNMTs-mediated hTERT promoter region methylation in breast cancer cells [90, 92, 93].

\section{Histone acetylation}

Histone acetyltransferases (HATs) and HDACs induce the acetylation and deacetylation of chromatin histone or non-histone proteins respectively, thereby modulating the expression or function of their targets. Histone acetylation or deacetylation has been shown to be associated with hTERT transcription and they seem to be a general underlying characteristic of human normal cells, telomerase-negative immortal cell lines and cancer cells [34, 94, 95]. Besides, core histones hyperacetylation at the hTERT promoter region is also related to its transcription in multiple human cells $[14,96]$. Treating telomerase-negative cells with the histone deacetylase inhibitor (HDACi) TSA causes hTERT mRNA upregulation and telomerase activation. In addition, MAD-mediated repression of the hTERT promoter requires histone deacetylase activity, whereas TSA-mediated derepression is not dependent on E-boxes [94]. Moreover, Won and colleagues show that SP1 and SP3 can interact with the hTERT promoter region, and recruit HDAC to deacetylate 
the nucleosomal histones and silence hTERT transcription in normal human somatic cells [35].

Several agents can regulate the hTERT promoter activity via acetylation or deacetylation. The HDACi TSA enhances histone acetylation at the proximal promoter region of hTERT, and directly transactivates the hTERT gene and upregulates hTERT expression. In addition, the effect of TSA is dependent on SP1 motifs [34]. Interestingly, Kretzner et al. reports that hTERT expression is reduced by the combination of aurora kinase inhibitors with the HDACi vorinostat in lymphoma cells. The reasons for the above discrepancy may imply the cell-type specificity and cellular context [97]. ChIP assay of the hTERT promoter region shows that SFN upregulates the level of active chromatin markers (such as acetyl-H3K9 and acetyl-H4), whereas it downregulates the level of suppressive chromatin markers (such as trimethyl-H3K9 and trimethyl-H3K27). The hyperacetylation induced by SFN accelerates the interaction of hTERT repressors (such as MAD1 and CTCF) with hTERT regulatory region. Silencing of CTCF rescues the SFN-induced hTERT transcription inhibition in breast cancer cells [91]. In another study, Meeran et al. reveals that both EGCG, the major component of green tea polyphenols, and its prodrug pro-EGCG decreases hTERT transcription in breast cancer cells. The reason is partially due to the hypomethylation of the hTERT promoter region and histone deacetylation [93]. EGCG and pro-EGCG decrease the levels of acetyl-H3, acetyl-H3K9, and acetyl-H4 at the hTERT promoter region. Structural alterations of chromatin facilitate the binding of several hTERT repressors such as E2F1 and MAD1 to the promoter region of hTERT. Silencing of E2F1 and MAD1 reverse the pro-EGCGmediated hTERT downregulation [90, 93].

Notably, methylation and acetylation are often crossed in the regulation of hTERT expression. Distinct modifications within the chromatin of the hTERT promoter correlate with different hTERT expression levels. For example, low hTERT expression is related to hypoacetylation of histone $\mathrm{H} 3$ and $\mathrm{H} 4$ and methylation of histone H3K9 in ALT cell lines. In contrast, hyperacetylation of $\mathrm{H} 3$ and $\mathrm{H} 4$, and methylation of H3K4 are associated with high hTERT expression in telomerase-positive tumor cells. However, methylation of H4K20 is specific to hTERT promoter region but is not involved in gene expression in ALT cells [98]. Besides, histone methyltransferase, SET and MYND domain-containing protein 3 (SMYD3), directly transactivates the hTERT gene. The association of SMYD3 with the hTERT promoter region is required for maintaining histone H3K4 trimethylation, which results in constitutive and inducible hTERT expression. SMYD3 downregulation abrogates trimethylation of H3K4, diminishes acetylation of histone $\mathrm{H} 3$, and alleviates the occupancy of c-MYC and SP1 at the
hTERT promoter region, ultimately resulting in reduced hTERT transcription [99]. In addition, depletion of SIRT1, a versatile HDAC, causes little change in CpG methylation patterns of the hTERT promoter region, and also does not affect hTERT mRNA stability. However, SIRT1 silencing is involved in a remarkable increase in acetylated histone H3K9 and a decrease in trimethyl histone H3K9 at the hTERT promoter region. These results indicate that SIRT1 regulates not only histone acetylation but also methylation of the hTERT promoter region [100]. Intriguingly, in addition to the direct epigenetic modification of hTERT, SIRT1 could also deacetylate $\mathrm{c}-\mathrm{MYC}$ and promote the interaction of c-MYC with its coactivator MAX, which facilitates the transactivation activity on the hTERT promoter region [101]. The HDACi TSA could induce site-specific CpGs demethylation on the hTERT promoter region by downregulating DNMT1. ChIP assays show that TSA-mediated 31st-33rd CpGs demethylation promotes the binding of CTCF to the hTERT promoter region, which results in the hTERT transcription repression in colon cancer cells [102].

\section{Regulation of hTERT at post-transcriptional levels Alternative mRNA splicing}

There are a plenty of alternative splicing variants for hTERT transcripts, but the regulatory mechanisms and functions are not totally clear. Among them, the function of two hTERT splicing variants, the $\alpha$-deletion and $\beta$-deletion forms have been well studied [103-105]. The $\alpha$-deletion form causes the loss of reverse transcriptase (RT) motif A and displays dominant negative effects on telomerase activity in human lung fibroblast cells and prostate cancer cells. However, the other two splicing variants $(\alpha+\beta$-deletion and $\beta$-deletion forms $)$ do not display any phenotype using the same models [103]. The $\beta$-deletion variant is the most extensively expressed hTERT splicing variant in stem cells and cancer cells, and it is degraded by nonsense-mediated decay [105, 106]. The $\beta$-deletion form creates a frameshift by skipping the exons 8 and 9 , and encounters a premature stop codon in exon 10. Splicing of the $\beta$-deletion variant is mediated by the splice factors HNRNPL, HNRNPH2, and SRSF11. The $\beta$-deletion hTERT overexpression competes with the WT hTERT to bind to hTERC, thereby suppressing telomerase activity. In addition, overexpressing $\beta$-deletion protein protects breast cancer cells from the cisplatin-induced apoptosis. These results reveal that the $\beta$-deletion hTERT splicing variant possesses a novel oncogenic function independent of maintaining telomere activity [105].

Different to most alternative splicing regulatory mechanisms, the splicing of hTERT mRNA is regulated by long-range interactions rather than by the intronic/ 
exonic elements close to the splice sites [107]. A block of 26 short repeats with a $38 \mathrm{nt}$ consensus sequence downstream of exon 6 (approximately $1900 \mathrm{nt}$ ) within the hTERT gene is called a block of repeats in intron 6 (B6, block 6), and a direct repeat (256 nt) in intron 6 or a direct repeat (256 nt) in intron 8 is called DR6 or DR8, respectively [107]. The number of B6 repeats varies from 18 to 38 repeats among different individuals, and altered repeats can cause diseases including cancers. This potential association between B6 repeats and cancer development requires further investigations [108]. B6 is required for $\beta$-deletion splicing, but DR6 and DR8 are not sufficient to create the skipping of exons 7 and 8 . However, they regulate the role of B6 to shift splicing to nonfunctional variants. Exchanging the positions of DR6 and DR8 or replacing each other reciprocally does not change the splicing patterns of hTERT. These results suggest that the intronic location instead of the sequence differences between DR6 and DR8 could determine their effect on alternative splicing, and that manipulating hTERT splicing may provide an avenue for chemotherapy and regenerative medicine [107].

Many factors can influence hTERT splicing. TGF- $\beta 1$ could downregulate c-MYC and subsequently decrease hTERT expression in human skin keratinocytes. Intriguingly, TGF- $\beta 1$ still inhibits the telomerase activity without hindering hTERT transcription by decreasing the full-length (FL) hTERT transcript and retaining high levels of the inactive $\beta$-deletion variant. Upon TGF- $\beta 1$ removal, the changes in the hTERT mRNA splicing pattern disappear, suggesting that alternative splicing may be a novel mechanism for TGF- $\beta 1$-mediated regulation of telomerase [109]. Besides, knockdown of neuro-oncological ventral antigen 1 (NOVA1) leads to a switch in hTERT splicing from the FL form towards a non-catalytic alternative variant and reduces telomerase activity by approximately $50 \%$. NOVA1 downregulation also significantly decreases cancer cell growth both in vitro and in vivo. What's more, NOVA1 facilitates the inclusion of exons in the hTERT reverse transcriptase domain, which produces FL hTERT transcripts. The $\beta$-deletion hTERT variant increases when NOVA1 decreases [110]. Interestingly, targeting NOVA1 can also downregulate the hTERT transcription, a possible reason is that NOVA1 may regulate the upstream transcription factors of hTERT in cancer cells [111]. Mechanistic research shows that when NOVA1 binds to the DR8 region of hTERT mRNA, it functions as a splicing enhancer to increase the FL hTERT mRNAs by including the exons 7 and 8 . These data verify the role of NOVA1 and DR8 in balancing the production of FL or spliced hTERT variants [110].

The alternative splicing of hTERT mRNA may provide a regulatory mechanism that could not be accomplished at the transcriptional level, and manipulating hTERT splicing may provide new insights into cancer therapeutics [107].Such subtle modulation may be especially important in hematopoietic stem cells where maintaining low telomerase activity might slow down but not abolish the telomere shortening [112]. Besides, alternative splicing can decease telomerase activity while exempting hTERT downregulation under conditions such as carcinogenesis [113, 114] or differentiation [115]. Regulation of hTERT splicing patterns is involved in several biological events, such as hypoxia or determination of immune cell fate. For instance, it has been known that HIF1 $\alpha$ elevates hTERT expression by activating its promoter [116, 117]. Hypoxia enhances the transcriptional activity of both hTERT and hTERC gene promoters. Interestingly, regulation of the hTERC gene is at the transcriptional level, while regulation of the hTERT gene is by an alternative splicing mechanism, which is related to a splicing pattern switch to the active WT hTERT form rather than simply upregulating total hTERT expression [118]. Besides, hypoxia causes high levels of nuclear hTERT and cell survival, and maintains the undifferentiated state. The splicing pattern of hTERT is distinct under different oxygen concentrations in human embryonic stem cells (hESCs). Hypoxia microenvironment decreases the FL and $\alpha$-deletion hTERT, while does not change the levels of $\beta$-deletion or the $\alpha+\beta$-deletion variants. In addition, steric blocking of $\alpha$-deletion and $\beta$-deletion splicing variants changes the hTERT variant patterns and results in hESCs differentiation [119]. Moreover, overexpressing the apoptotic endonuclease EndoG in human $\mathrm{CD} 4^{+} \mathrm{T}$ cells reduces the expression of the active FL hTERT variant and enhances the expression of the inactive $\beta$-deletion variant, which results in the decreased telomerase activity and a replicative senescent state [120].

\section{Non-coding RNAs microRNA}

It has been reported that hTERT can be regulated by different microRNAs (miRNAs) in many types of cancers (Table 1). MiRNAs influence the expression of hTERT proteins mainly by directly binding to its 3 - untranslated region ( $3^{\prime}$-UTR). This changes the tumor cell proliferation, apoptosis, migration, invasion and chemosensitivity. For instance, miR-138 is significantly downregulated in anaplastic thyroid carcinoma (ATC) cell lines. Overexpression of miR-138 reduces the hTERT protein level through binding to its 3'-UTR [121]. Besides, miR-615-3p locates in an intron of the HOXC5 gene and negatively regulates hTERT by targeting its 3 '-UTR. Furthermore, miR-615-3p and HOXC5 make a feed-forward loop that orchestrates transcriptional and post-transcriptional suppression of hTERT during cellular differentiation [134]. Among the known miRNAs that regulate hTERT, 
Table 1 The MiRNAs that regulate hTERT

\begin{tabular}{|c|c|c|c|}
\hline MiRNA & Mechanism & Cancer cell types & Ref. \\
\hline \multicolumn{4}{|l|}{ Negative regulators } \\
\hline miR-138 & targeting the $3^{\prime}$-UTR of hTERT & anaplastic thyroid carcinoma (ATC) & [121] \\
\hline miR-138-5p and miR-422a & potentially inhibits hTERT & colorectal cancer (CRC) & [122] \\
\hline miR-299-3p & targeting the $3^{\prime}$-UTR of hTERT & laryngeal cancer & [123] \\
\hline miR-512-5p & targeting the $3^{\prime}$-UTR of hTERT & head and neck squamous cell carcinoma (HNSCC) & [124] \\
\hline miR-661 & targeting the $3^{\prime}$-UTR of hTERT & glioma cells & [125] \\
\hline miR-1182 & targeting the open reading frame (ORF) of hTERT & gastric cancer (GC) & [126] \\
\hline miR-1182 & targeting the $3^{\prime}$-UTR of hTERT & bladder cancer (BC) & [127] \\
\hline miR-1207-5p and miR-1266 & targeting the $3^{\prime}$-UTR of hTERT & gastric cancer (GC) & [128] \\
\hline miR-491-5p & targeting the $3^{\prime}$-UTR of hTERT & cervical cancer & [129] \\
\hline miR-133a, miR-138, and miR-491 & targeting the $3^{\prime}$-UTR of hTERT & cervical cancer & [130] \\
\hline miR-532 and miR-3064 & targeting the 3 '-UTR of hTERT & ovarian cancer & [131] \\
\hline miR-498 & targeting the $3^{\prime}$-UTR of hTERT & ovarian cancer & [132] \\
\hline miR-34a & targeting the FOXM1/c-MYC pathway & hepatocellular carcinoma (HCC) & [133] \\
\hline miR-615-3p & targeting the $3^{\prime}$-UTR of hTERT & multiple kinds of cancers & [134] \\
\hline \multicolumn{4}{|l|}{ Positive regulators } \\
\hline miR-346 & competing with miR-138 & cervical cancer & [135] \\
\hline miR-19b & inhibition of PITX1 & melanoma & [136] \\
\hline miR-202 & via the MXD1-MYC/MAX pathway & pancreatic cancer & [137] \\
\hline miR-21 & via the PTEN/ERK1/2 pathway & colorectal cancer (CRC) & {$[138,139]$} \\
\hline
\end{tabular}

miR-1182 has dual effects in downregulating hTERT. On the one hand, it targets the open reading frame (ORF) of hTERT, thereby reducing proliferation and metastasis of gastric cancer cells. On the other hand, it directly targets the 3 '-UTR of hTERT to enhance the chemosensitivity of bladder cancer cells $[126,127]$. In addition to direct targeting, miRNAs can regulate hTERT indirectly via influencing the upstream regulators (transcription factors, etc.) of hTERT. For example, miR-34a targets FOXM1 and c-MYC, both of which can activate hTERT transcription and subsequently modulate telomerase activity and cellular senescence [133].

Typically, miRNAs downregulate hTERT by targeting its 3'-UTR. Unconventionally, there are also miRNAs that can positively regulate the expression of hTERT. For instance, in cervical cancer cells, miR-346 and miR-138 compete with each other to bind the common 3 '-UTR region of hTERT mRNA. miR-138 suppresses the expression of hTERT in an AGO2-dependent manner. In contrast, miR-346 can upregulate hTERT [135]. The mechanism lies in GRSF1 binding to the miR-346 middle sequence motif which facilitates to recruitment of hTERT mRNA to ribosomes and promotes hTERT mRNA translation in an AGO2-independent manner. Interestingly, replacing the middle sequence of miR-138 with that of miR-346 upregulates hTERT in a
GRSF1-dependent manner [135]. PITX1 is a suppressor gene of hTERT, and PITX1 is a direct target of miR-19b. Therefore, miR-19b enhances the expression of hTERT by alleviating the inhibitory effect of PITX1 on hTERT [136]. MXD1 is the target gene of miR-202 and pre-miR-202 overexpression decreases the level of MXD1. Besides, MXD1 binds to the promoter region of hTERT and reduces c-MYC binding to the hTERT promoter region, leading to the decreased hTERT mRNA expression. These findings suggest that miR-202 may target MXD1 to increase hTERT expression [137]. In addition, it has been reported that PTEN is a miR-21 target gene in CRC cell lines [138]. Further study reveals that miR-21 positively regulates hTERT expression through the PTEN/ERK1/2 signaling pathway. Moreover, hTERT inversely correlates with PTEN in high miR-21 RNA-expressing CRC tissues [139]. The miRNAs that negatively or positively regulate the expression of hTERT are listed in Table 1 [121-139].

\section{Long non-coding RNA}

Long non-coding RNAs (lncRNAs) are a set of transcripts longer than $200 \mathrm{nt}$ with no or limited protein coding function. LncRNAs display their functions via different manners and regulation of gene expressions by lncRNAs is emerging as a novel and critical way [140, 
141]. The hTERT antisense promoter-associated RNA (hTAP-AS) is an antisense transcript in the promoter region of hTERT which is located in both the cytoplasm and the nucleus. The expression of hTAP-AS is negatively related with hTERT in multiple human tumor types. Overexpression of hTAP-AS decreases hTERT while knockdown of hTAP-AS increases hTERT. Interestingly, the hTERT promoter mutation $(-124 \mathrm{C}>\mathrm{T})$ remarkably upregulates hTERT but not hTAP-AS [142]. As the star molecules, both of the IncRNA RNA HOTAIR and MALAT1 can occupy the promoter region of estrogen target genes such as hTERT under basal conditions. Interestingly, estrogen markedly enhances the recruitment of HOTAIR while it inhibits the recruitment of MALAT1 onto hTERT promoter region. Besides, interfering HOTAIR delays the response of estrogen to hTERT while MALAT1 depletion increases hTERT mRNA levels in prostate cancer cells [143]. In esophageal carcinoma cells, treatment with $\beta$-elemene significantly suppresses cell proliferation and the level of hTERT while dramatically upregulates the lncRNA CDKN2B-AS1. When transfection with the siRNA against CDKN2B-AS1, the cell proliferation rate and hTERT expression are increased in the presence of $\beta$-elemene, indicating that the IncRNA CDKN2B-AS1-mediated downregulation of hTERT may play a crucial role in the anticancer effect of $\beta$-elemene [144]. As for the lncRNA BC032469, it is highly expressed in tissues of gastric cancer patient and predicts a poor prognosis. BC032469 serves as a competitive endogenous RNA (ceRNA) to suppress miR-1207-5p-mediated hTERT inhibition. Thus, silencing BC032469 remarkably inhibits proliferation of gastric cancer cells in vitro and in vivo [145]. In a study by $\mathrm{Pu}$ et al., the lncRNA RNA CUDR forms a complex with Cyclin D1 to enhance the expression of H19. Overexpression of $\mathrm{H} 19$ enhances the interaction between hTERT and TERC, and weakens the association between hTERT and TERRA, thereby heightening telomerase activity. Besides, hTERT upregulation plays an important role in CUDR-mediated liver cancer cell stemness [146]. Redon and colleagues find that repeats $\left(5^{\prime}\right.$-UUAGGG-3') of the large non-coding RNA telomeric repeat containing RNA (TERRA) binds to hTERT and interacts with the telomerase RNA template hTERC through a base pairing mechanism. TERRA contacts the hTERT independently of hTERC. This study indicates that TERRA is a natural ligand and negative regulator of human telomerase [147].

In addition to traditional IncRNA RNAs, circular RNAs (circRNAs) represent a new direction of gene regulation. The circular RNA hsa_circ_0020397 upregulates the expression of hTERT by sequestering miR-138 (the negative regulator of hTERT). The pro-invasion effect of hsa_circ_0020397 is inhibited when hTERT is silenced, suggesting that the circRNA hsa_circ_0020397 promotes cancer cell invasion partially by regulating the expression of miR-138 target genes, such as hTERT [148]. The lncRNAs that regulate the expression (activity) of hTERT (telomerase) are listed in Table 2 [142-148].

\section{Regulation of hTERT protein at post-translational levels}

Similar to other molecules, the post-translational modifications (PTMs) of hTERT could influence its protein stability, subcellular localization and subsequently change its protein levels or the telomerase activity. Currently, the post-translational regulations of hTERT mainly focus on phosphorylation and ubiquitination.

\section{Phosphorylation}

Several studies have revealed that hTERT can be modified by phosphorylation. A prominent effect of phosphorylation is the cellular localization change of hTERT.

Table 2 The IncRNAs that regulate hTERT

\begin{tabular}{|c|c|c|c|c|}
\hline LncRNA & Effects on hTERT/telomerase & Mechanism & Human cell model & Ref. \\
\hline hTAP-AS & hTERT expression $\downarrow$ & not stated & embryonic kidney cells & [142] \\
\hline HOTAIR & $\begin{array}{l}\text { positive effect on hTERT in respond } \\
\text { to estrogen }\end{array}$ & $\begin{array}{l}\text { regulates the estrogen target genes } \\
\text { positively by estrogen-modulated } \\
\text { chromatin remodeling }\end{array}$ & prostate cancer cells & [143] \\
\hline MALAT1 & hTERT transcription $\downarrow$ & functions on hTERT promoter & prostate cancer cells & [143] \\
\hline CDKN2B-AS1 & hTERT expression $\downarrow$ & not stated & esophageal squamous carcinoma cells & [144] \\
\hline BC032469 & hTERT expression $\uparrow$ & functions as a sponge for miR-1207-5p & gastric cancer cells & [145] \\
\hline TERRA & $\begin{array}{l}\text { functions as a telomerase ligand and } \\
\text { direct telomerase inhibitor }\end{array}$ & $\begin{array}{l}\text { TERRA base repeats pair with hTERC, } \\
\text { TERRA contacts with hTERT protein }\end{array}$ & embryonic kidney cells & [147] \\
\hline CUDR & $\begin{array}{l}\text { the binding of hTERT/hTERC } \uparrow \text { the } \\
\text { binding of hTERT/TERRA } \downarrow \text { telomerase } \\
\text { activity } \uparrow\end{array}$ & $\begin{array}{l}\text { the CUDR-CyclinD1 complex enhances } \\
\text { the expression of } \mathrm{H} 19\end{array}$ & liver cancer stem cells & [146] \\
\hline hsa_circ_0020397 & hTERT expression $\uparrow$ & inhibits miR-138 activity and its targets & colorectal cancer cells & [148] \\
\hline
\end{tabular}

$\uparrow$ Promoting effect, $\downarrow$ Suppressing effect 
The most reported kinases that phosphorylate hTERT are AKT, PKC and SRC kinases.

As a multifunctional kinase, AKT kinase phosphorylates and regulates hTERT in various ways. The hTERT peptide $\left({ }^{817}\right.$ AVRIRGKSYV ${ }^{826}$ ) could be phosphorylated by the activated AKT kinase in vitro, which plays a crucial role in maintaining the telomere length and heightening telomerase activity [149]. Besides, AKT-mediated hTERT phosphorylation at serine 227 plays a significant role in directing its nuclear translocation. Interestingly, $\mathrm{Ser}^{227}$ phosphorylation of hTERT is equivalently necessary with the bipartite nuclear localization signal (NLS) motifs for efficient hTERT nuclear localization and immortalization of human foreskin fibroblast cells [150]. Furthermore, the $\mathrm{Ser}^{227}$ phosphorylation by AKT increases the binding affinity of hTERT with the nuclear import receptors importin- $\alpha$, which promotes nuclear import of hTERT, thereby increasing telomerase activity [151]. In addition, hTERT phosphorylation by the PKC isoenzymes $\alpha, \beta, \delta, \varepsilon$ and $\zeta$ is vital for maintaining telomerase holoprotein integrity in head and neck cancer cells, which finally results in telomerase activation and oncogenesis. Inhibition of telomerase by dephosphorylating PKC significantly chemosensitizes cisplatin [152]. Interestingly, in human breast cancer cells, although all PKC isoforms may potentially regulate telomerase activity, only $\mathrm{PKC} \alpha$ interacts with partially purified telomerase. PKC $\alpha$ phosphorylates while PP2A dephosphorylates hTERT and human telomerase-associated protein 1 (hTEP1), and the hTERT/hTEP1 phosphorylation status by reversible regulation of $\mathrm{PKC} \alpha$ and PP2A dramatically determines the telomerase activity in breast cancer cells [153]. These evidences imply that PKC differentially regulates hTERT in distinct models. Moreover, upon oxidative stress, hTERT translocates from nuclear to cytoplasm. This process depends on GTPase Ran through the export receptor CRM1 as well as tyrosine $707\left(\mathrm{Tyr}^{707}\right)$ phosphorylation by the SRC kinase family. The specific SRC kinase inhibitor PP1 weakens hTERT nuclear export and decreases the antiapoptotic function of hTERT [154]. Meanwhile, the SRC kinase colocalizes with hTERT in mitochondria in primary human endothelial cells. During $\mathrm{H}_{2} \mathrm{O}_{2}$ stimulation, AKT1 is inactivated and the SRC kinase is activated. In the meantime, mitochondrial hTERT is decreased, which depends on SRC kinase-mediated $\mathrm{Tyr}^{707}$ phosphorylation [155]. As a protein tyrosine phosphatase that counteracts the function of the SRC kinase family, SHP-2 could complex with hTERT. Overexpression of wild-type, but not catalytically inactive, SHP-2 suppresses $\mathrm{H}_{2} \mathrm{O}_{2}$-induced hTERT nuclear export via regulating $\mathrm{Tyr}^{707}$ phosphorylation of hTERT [156]. The c-ABL tyrosine kinase, a DNA damage effector, could also induce tyrosine phosphorylation of hTERT upon ionizing radiation. c-ABL-mediated hTERT phosphorylation finally represses telomerase activity [157]. Interestingly, inhibition of c-ABL does not prevent $\mathrm{H}_{2} \mathrm{O}_{2}$-induced hTERT tyrosine phosphorylation [154]. Liu et al. reveals that during human $\mathrm{CD}_{4}^{+} \mathrm{T}$ lymphocytes activation, $\mathrm{CD} 4^{+} \mathrm{T}$ cells regulate telomerase function independent of the hTERT protein levels, nevertheless, hTERT phosphorylation and subsequent nuclear translocation may play an important role in regulating telomerase function [158]. In addition, high throughput screening suggests that there may be other potential phosphorylation sites within the hTERT protein, which warrants further investigations $[159,160]$.

\section{Ubiquitination}

To date, there are only few reports that have investigated the ubiquitination modifications of hTERT. Kim et al. shows that breaking HSP90 function with geldanamycin induces ubiquitination and subsequent proteasome-mediated degradation of hTERT. As an E3 ubiquitin ligase, Makorin RING finger protein 1 (MKRN1) mediates the ubiquitination of hTERT. Overexpression of MKRN1 could promote hTERT degradation and downregulate telomerase activity and telomere length [161]. In addition, Oh et al. reveals that the E3 ligase HDM2 could polyubiquitinate hTERT mainly at the five lysines in its $\mathrm{N}$-terminus, which further leads to its proteasome-dependent degradation. HDM2 depletion or transfection with the HDM2-resistant hTERT mutant reinforces the cellular antiapoptotic effects [162]. Moreover, CHIP and HSP70 associate with hTERT and repress its nuclear translocation by disaggregating hTERT with p23 rather than HSP90. CHIP overexpression promotes degradation of hTERT in the cytoplasm, thus suppressing the telomerase activity. Notably, CHIP can regulate the hTERT chaperone complexes in a cell cycle-dependent manner [163]. The currently reported PTMs of hTERT are listed in Table 3 [149-158, 161-163].

\section{Conclusions and future investigations}

As the core subunit of telomerase, hTERT is normally expressed in highly self-renewal cells and absent in normal somatic cells. Deregulations of hTERT significantly promote cancer initiation and development. Up to now, a large range of mechanisms for hTERT regulation in both normal and cancer cells have been revealed, which have provided significant insights into the hTERT-based therapeutics. Our review has summarized different layers of hTERT regulation, including transcriptional (promoter mutation, promoter region methylation and histone acetylation), post-transcriptional (alternative splicing, non-coding RNAs) and post-translational levels (phosphorylation and ubiquitination), which may provide comprehensive perspectives for further basic and translational investigations regarding hTERT. Interestingly, these mechanisms are not isolated, but interact with each other. For instance, binding of the 
Table 3 The PTMs of hTERT

\begin{tabular}{|c|c|c|c|c|}
\hline Enzyme & Site & Effects on hTERT/telomerase & Human cell model & Ref. \\
\hline \multicolumn{5}{|c|}{ PTMs: Phosphorylation } \\
\hline AKT & Ser 824 & telomerase activity $\uparrow$ & melanoma cells & [149] \\
\hline AKT & Ser 227 & $\begin{array}{l}\text { hTERT nuclear translocation } \uparrow \text { cell } \\
\text { immortalization } \uparrow\end{array}$ & $\begin{array}{l}\text { lung carcinoma cells and foreskin fibroblast } \\
\text { cells }\end{array}$ & [150] \\
\hline AKT & Ser 227 & $\begin{array}{l}\text { hTERT binding with importin-a } \uparrow \text { hTERT } \\
\text { nuclear import } \uparrow \text { telomerase activity } \uparrow\end{array}$ & breast cancer cells & [151] \\
\hline PKCa, $\beta, \delta, \varepsilon, \zeta$ & Unclear & $\begin{array}{l}\text { hTERT association with HSP90 } \uparrow \\
\text { telomerase holoprotein integrity } \uparrow \\
\text { telomerase activation } \uparrow \text { chemosensitivity } \\
\text { to cisplatin } \downarrow\end{array}$ & head and neck cancer cells & [152] \\
\hline PKCa & Unclear & telomerase activity $\uparrow$ & breast cancer cells & [153] \\
\hline SRC & Tyr 707 & $\begin{array}{l}\text { cytoplasm translocation } \uparrow \text { antiapoptotic } \\
\text { function } \uparrow\end{array}$ & embryonic kidney cells & [154] \\
\hline SRC & Tyr 707 & mitochondrial hTERT $\downarrow$ & umbilical and vein endothelial cells & [155] \\
\hline$c-A B L$ & Tyr & telomerase activity $\downarrow$ & embryonic kidney cells and breast cancer cells & [157] \\
\hline Unclear & Unclear & nuclear translocation $\uparrow$ & $\mathrm{CD}^{+} \mathrm{T}$ cells & [158] \\
\hline \multicolumn{5}{|c|}{ PTMs: Dephosphorylation } \\
\hline SHP-2 & Tyr 707 & $\begin{array}{l}\text { SRC kinase function } \downarrow \text { H2O2-induced } \\
\text { hTERT nuclear export } \downarrow \text { nuclear } \\
\text { telomerase activity } \uparrow\end{array}$ & endothelial cells & [156] \\
\hline \multicolumn{5}{|c|}{ PTMs: Ubiquitination } \\
\hline MKRN1 & Unclear & $\begin{array}{l}\text { hTERT degradation } \uparrow \text { telomerase } \\
\text { activity } \downarrow \text { telomere length } \downarrow\end{array}$ & lung carcinoma cells & [161] \\
\hline HDM2 & N-Lys 78, 94, 236, 339, 348 & $\begin{array}{l}\text { hTERT degradation } \uparrow \text { protection against } \\
\text { apoptosis } \downarrow\end{array}$ & $\begin{array}{l}\text { colon cancer, lung carcinoma, osteosarcoma } \\
\text { and embryonic kidney cells }\end{array}$ & [162] \\
\hline $\mathrm{CHIP}$ & Unclear & $\begin{array}{l}\text { hTERT associating with p23 } \downarrow \text { hTERT } \\
\text { nuclear translocation } \downarrow \text { hTERT } \\
\text { degradation } \uparrow\end{array}$ & lung carcinoma cells & [163] \\
\hline
\end{tabular}

$\uparrow$ Promoting effect, $\downarrow$ Suppressing effect

transcription factors to the hTERT promoter region could influence the alternative splicing of hTERT transcripts $[116,117,119]$. Besides, the hTERT promoter region methylation pattern can affect the binding of several transcription factors to the hTERT promoter region $[79,83]$. Therefore, more studies are needed to fully clarify the possible crosstalk between these distinct mechanisms, and a better understanding of hTERT regulation elements are crucial for providing novel approaches in treating cancers.

A plenty of studies have illustrated the significant roles of hTERT regulation in human cancers. However, numerous questions still remain to be clarified. For example, what causes the significantly different frequencies of hTERT promoter mutation between distinct cancer types. In addition, although the mutant hTERT promoter sometimes coexists with other mutations, the detailed relationships (upstream or downstream) and the corresponding regulatory mechanisms are still unknown. Furthermore, whether mutant hTERT promoter targeted strategies are sufficient to suppress telomerase activity in cancer therapeutics also needs further investigations. At another layer, the post-translational modifications of hTERT dramatically influence the protein stabilization and localization of hTERT. Notably, there are few studies about the methylation, acetylation or SUMOylation modifications of the hTERT protein, and studies in these fields require further deep investigations.

Due to its critical roles in carcinogenesis and cancer progression, hTERT-based diagnosis and therapies have emerged and are worthy of expectations. The mutant hTERT promoter is a relatively unique feature in cancer mutations. Whether it can be a diagnostic biomarker used in liquid biopsies, such as detecting in exosomes or in circulating tumor cells, needs further explorations. In addition, hTERT-based agents [164, 165], peptide epitopes $[166,167]$ or suicide gene therapy [168] may have potential therapeutic effects. However, challenges still remain, because large-scale preclinical studies on drug efficacy, safety and tolerance of patients should be strictly examined. Another critical question that remains is that the intact crystal structure of hTERT is still not fully 
illuminated, which limits the precise structure-based drug designs for hTERT inhibitors. Taken together, further studies that elucidate these questions may accelerate the application of hTERT-based cancer diagnosis as well as therapeutics.

\section{Abbreviations}

3'-UTR: 3'-untranslated region; AP-1: Activator protein 1; ATC: Anaplastic thyroid carcinoma; BC: Bladder cancer; ccRCC: Clear cell renal cell cancer; ceRNA: Competitive endogenous RNA; circRNAs: Circular RNAs; DNMT1: DNA methyltransferase 1; DNMT3a: DNA methyltransferase 3a; ETS: E-twenty-six; FL: Full-length; GBM: Glioblastoma multiforme; HATs: Histone acetyltransferases; HCC: Hepatocellular carcinoma; HDAC: Histone deacetylase; HDACi: Histone deacetylase inhibitor; hESCs: Human embryonic stem cells; HIF2a: Hypoxia-inducible factor 2-alpha; hTAP-AS: hTERT antisense promoter-associated RNA; hTEP1: Human telomerase-associated protein 1 hTERC: Human telomerase RNA; hTERT: Human telomerase reverse transcriptase; IncRNAs: Long non-coding RNAs; MKRN1: Makorin RING finger protein 1; NLS: Nuclear localization signal; NOVA1: Neuro-oncological ventral antigen 1; ORF: Open reading frame; OS: Overall survival; PTC: Papillary thyroid carcinoma; PTMs: Post-translational modifications; RA: Retinoic acid; RPC: Renal pelvic cancer; RT: Reverse transcriptase; SFN: Sulforaphane; SIRT1: Sirtuin 1; SMYD3: SET and MYND domain-containing protein 3; SP1: Specificity protein 1; TSA: Trichostatin A; TSS: Transcriptional starting site; WT: Wild-type; WT1: Wilms tumor protein

\section{Acknowledgements}

We thank for the National Natural Science Foundation of China (No. 81772534) to support this work.

\section{Funding}

This work was supported by the National Natural Science Foundation of China (No. 81772534).

\section{Availability of data and materials}

Not applicable.

\section{Authors' contributions}

$M-M J, X C, S Z, S-M Y$ and $X-Z L$ were involved in the design, drafting and revision of the manuscript. CL, G-BL, Y-RW, C-HL and C-JH participated in the editing and revision of the manuscript. All authors read and approved the manuscript.

\section{Authors' information}

Jie M., Chang X., Yang S. and Li X. are all physician scientists.

\section{Ethics approval and consent to participate}

Not applicable.

\section{Consent for publication}

Not applicable.

\section{Competing interests}

The authors declare that they have no competing interests.

\section{Publisher's Note}

Springer Nature remains neutral with regard to jurisdictional claims in published maps and institutional affiliations.

\section{Author details}

'Department of Gastroenterology, Xingiao Hospital, Third Military Medical University (Army Medical University), Chongqing 400037, China. ${ }^{2}$ Teaching evaluation center of Third Military Medical University (Army Medical University), Chongqing 400038, China.
Received: 16 November 2018 Accepted: 17 May 2019

Published online: 11 June 2019

\section{References}

1. Blackburn EH. Switching and signaling at the telomere. Cell. 2001;106: $661-73$.

2. Liu L, Saldanha SN, Pate MS, Andrews LG, Tollefsbol TO. Epigenetic regulation of human telomerase reverse transcriptase promoter activity during cellular differentiation. Genes Chromosomes Cancer. 2004;41:26-37. https://doi.org/10.1002/gcc.20058.

3. Liu L, Lai S, Andrews LG, Tollefsbol TO. Genetic and epigenetic modulation of telomerase activity in development and disease. Gene. 2004;340:1-10 https://doi.org/10.1016/.j.gene.2004.06.011.

4. Kim NW, et al. Specific association of human telomerase activity with immortal cells and cancer. Science. 1994;266:2011-5.

5. Wright WE, Piatyszek MA, Rainey WE, Byrd W, Shay JW. Telomerase activity in human germline and embryonic tissues and cells. Dev Genet. 1996;18: 173-9. https://doi.org/10.1002/(SICI)1520-6408(1996)18:2<173::AID-DVG10>3. $0 . \mathrm{CO} ; 2-3$.

6. Cukusic A, Skrobot Vidacek N, Sopta M, Rubelj I. Telomerase regulation at the crossroads of cell fate. Cytogenet Genome Res. 2008;122:263-72. https://doi.org/10.1159/000167812.

7. Kyo S, Takakura M, Fujiwara T, Inoue M. Understanding and exploiting hTERT promoter regulation for diagnosis and treatment of human cancers. Cancer Sci. 2008;99:1528-38. https://doi.org/10.1111/j.1349-7006.2008.00878.x.

8. Shay JW, Wright WE, Werbin H. Defining the molecular mechanisms of human cell immortalization. Biochim Biophys Acta. 1991;1072:1-7.

9. Jafri MA, Ansari SA, Alqahtani MH, Shay JW. Roles of telomeres and telomerase in cancer, and advances in telomerase-targeted therapies. Genome Med. 2016;8:69. https://doi.org/10.1186/s13073-016-0324-x.

10. Feng J, et al. The RNA component of human telomerase. Science. 1995;269: 1236-41.

11. Nakamura TM, et al. Telomerase catalytic subunit homologs from fission yeast and human. Science. 1997;277:955-9.

12. Wu KJ et al. Direct activation of TERT transcription by c-MYC. Nat Genet. 1999;21:220-4. https://doi.org/10.1038/6010.

13. Cong YS, Wen J, Bacchetti S. The human telomerase catalytic subunit hTERT: organization of the gene and characterization of the promoter. Hum Mol Genet. 1999:8:137-42.

14. Xu D, et al. Switch from Myc/max to Mad1/max binding and decrease in histone acetylation at the telomerase reverse transcriptase promoter during differentiation of HL60 cells. Proc Natl Acad Sci U S A. 2001;98:3826-31. https://doi.org/10.1073/pnas.071043198.

15. Kyo S, et al. Sp1 cooperates with c-Myc to activate transcription of the human telomerase reverse transcriptase gene (hTERT). Nucleic Acids Res. 2000;28:669-77.

16. Oh ST, Kyo S, Laimins LA. Telomerase activation by human papillomavirus type 16 E6 protein: induction of human telomerase reverse transcriptase expression through Myc and GC-rich Sp1 binding sites. J Virol. 2001;75: 5559-66. https://doi.org/10.1128/JVI.75.12.5559-5566.2001.

17. Faiola F, et al. Dual regulation of c-Myc by p300 via acetylation-dependent control of Myc protein turnover and coactivation of Myc-induced transcription. Mol Cell Biol. 2005;25:10220-34. https://doi.org/10.1128/MCB. 25.23.10220-10234.2005.

18. Yamashita S, et al. SIRT1 prevents replicative senescence of normal human umbilical cord fibroblast through potentiating the transcription of human telomerase reverse transcriptase gene. Biochem Biophys Res Commun. 2012:417:630-4. https://doi.org/10.1016/j.bbrc.2011.12.021.

19. Yang $\mathrm{H}$, et al. Aurora-a kinase regulates telomerase activity through c-Myc in human ovarian and breast epithelial cells. Cancer Res. 2004:64:463-7.

20. Aravindan N, Veeraraghavan J, Madhusoodhanan R, Herman TS, Natarajan M. Curcumin regulates low-linear energy transfer $y$-radiationinduced NFKB-dependent telomerase activity in human neuroblastoma cells. Int J Radiat Oncol Biol Phys. 2011;79:1206-15. https://doi.org/10. 1016/.ijrobp.2010.10.058.

21. Papanikolaou V, et al. hTERT regulation by NF-kB and c-myc in irradiated HER2-positive breast cancer cells. Int J Radiat Biol. 2011;87:609-21. https:// doi.org/10.3109/09553002.2011.572112.

22. Natarajan M, Mohan S, Konopinski R, Otto RA, Herman TS. Induced telomerase activity in primary aortic endothelial cells by low-LET $\gamma$-radiation 
is mediated through NF-KB activation. Br J Radiol. 2008;81:711-20. https:// doi.org/10.1259/bjr/57867919.

23. Sheng $W-Y$, Chen $Y-R$, Wang T-CV. A major role of PKC $\theta$ and NFkB in the regulation of hTERT in human T lymphocytes. FEBS Lett. 2006;580:6819-24. https://doi.org/10.1016/j.febslet.2006.11.044.

24. Sinha-Datta U. Transcriptional activation of hTERT through the NF- B pathway in HTLV-I-transformed cells. Blood. 2004;104:2523-31. https://doi. org/10.1182/blood-2003-12-4251.

25. Saretzki G, Chung SS, Aroh C, Vadgama JV. Constitutive activation of STAT3 signaling regulates hTERT and promotes stem cell-like traits in human breast Cancer cells. PLoS One. 2013;8:e83971. https://doi.org/10.1371/ journal.pone.0083971.

26. Konnikova L, Simeone MC, Kruger MM, Kotecki M, Cochran BH. Signal transducer and activator of transcription 3 (STAT3) regulates human telomerase reverse transcriptase (hTERT) expression in human cancer and primary cells. Cancer Res. 2005;65:6516-20. https://doi.org/10.1158/0008-5472.CAN-05-0924.

27. Zhang Y, et al. E2F1 acts as a negative feedback regulator of c-Mycinduced hTERT transcription during tumorigenesis. Oncol Rep. 2014;32:1273-80. https://doi.org/10.3892/or.2014.3287.

28. Crowe DL, Nguyen DC, Tsang KJ, Kyo S. E2F-1 represses transcription of the human telomerase reverse transcriptase gene. Nucleic Acids Res. 2001;29:2789-94.

29. Zhu J, Blenis J, Yuan J. Activation of PI3KJAkt and MAPK pathways regulates Myc-mediated transcription by phosphorylating and promoting the degradation of Mad1. Proc Natl Acad Sci U S A. 2008;105:6584-9. https:// doi.org/10.1073/pnas.0802785105.

30. Gunes C, Lichtsteiner S, Vasserot AP, Englert C. Expression of the hTERT gene is regulated at the level of transcriptional initiation and repressed by Mad1. Cancer Res. 2000;60:2116-21.

31. Oh S, Song YH, Yim J, Kim TK. Identification of mad as a repressor of the human telomerase (hTERT) gene. Oncogene. 2000;19:1485-90. https://doi. org/10.1038/sj.onc.1203439.

32. Knight JS, Cotter MA, Robertson ES. The latency-associated nuclear antigen of Kaposi's sarcoma-associated herpesvirus Transactivates the telomerase reverse transcriptase promoter. J Biol Chem. 2001;276:22971-8. https://doi. org/10.1074/jbc.M101890200.

33. Liu L, et al. MCAF1/AM is involved in Sp1-mediated maintenance of cancerassociated telomerase activity. J Biol Chem. 2009;284:5165-74. https://doi. org/10.1074/jbc.M807098200.

34. Hou M, et al. The histone deacetylase inhibitor Trichostatin a Derepresses the telomerase reverse transcriptase (hTERT) gene in human cells. Exp Cell Res. 2002;274:25-34. https://doi.org/10.1006/excr.2001.5462.

35. Won J, Yim J, Kim TK. Sp1 and Sp3 recruit histone deacetylase to repress transcription of human telomerase reverse transcriptase (hTERT) promoter in Normal human somatic cells. J Biol Chem. 2002;277:38230-8. https://doi. org/10.1074/jbc.M206064200.

36. Takakura M, Kyo S, Inoue M, Wright WE, Shay JW. Function of AP-1 in transcription of the telomerase reverse transcriptase gene (TERT) in human and mouse cells. Mol Cell Biol. 2005;25:8037-43. https://doi.org/10.1128/ MCB.25.18.8037-8043.2005.

37. Kuhlmann AS, et al. HTLV-1 HBZ cooperates with JunD to enhance transcription of the human telomerase reverse transcriptase gene (hTERT) Retrovirology. 2007;4:92. https://doi.org/10.1186/1742-4690-4-92.

38. Lou F, et al. The opposing effect of hypoxia-inducible factor-2alpha on expression of telomerase reverse transcriptase. Mol Cancer Res. 2007;5:793800. https://doi.org/10.1158/1541-7786.MCR-07-0065.

39. Heidenreich B, Kumar R. TERT promoter mutations in telomere biology. Mutat Res. 2017;771:15-31. https://doi.org/10.1016/j.mrrev.2016.11.002.

40. Liu T, et al. The age- and shorter telomere-dependent TERT promoter mutation in follicular thyroid cell-derived carcinomas. Oncogene. 2014;33: 4978-84. https://doi.org/10.1038/onc.2013.446.

41. Vinagre $\mathrm{J}$, et al. Frequency of TERT promoter mutations in human cancers. Nat Commun. 2013;4:2185. https://doi.org/10.1038/ncomms3185.

42. Nault JC, et al. High frequency of telomerase reverse-transcriptase promoter somatic mutations in hepatocellular carcinoma and preneoplastic lesions. Nat Commun. 2013;4:2218. https://doi.org/10.1038/ncomms3218.

43. Liu X, et al. Highly prevalent TERT promoter mutations in bladder cancer and glioblastoma. Cell Cycle. 2013;12:1637-8. https://doi.org/10.4161/cc.24662.

44. Huang FW, et al. Highly recurrent TERT promoter mutations in human melanoma. Science. 2013;339:957-9. https://doi.org/10.1126/science.1229259.

45. Rachakonda PS, et al. TERT promoter mutations in bladder cancer affect patient survival and disease recurrence through modification by a common polymorphism. Proc Natl Acad Sci U S A. 2013;110:17426-31. https://doi. org/10.1073/pnas.1310522110.

46. Wang $\mathrm{K}$, et al. TERT promoter mutations in renal cell carcinomas and upper tract urothelial carcinomas. Oncotarget. 2014;5:1829-36. https://doi.org/10. 18632/oncotarget.1829.

47. Killela PJ, et al. TERT promoter mutations occur frequently in gliomas and a subset of tumors derived from cells with low rates of selfrenewal. Proc Natl Acad Sci U S A. 2013;110:6021-6. https://doi.org/10. 1073/pnas.1303607110.

48. Liu T, Liang X, Bjorkholm M, Jia J, Xu D. The absence of TERT promoter mutations in primary gastric cancer. Gene. 2014;540:266-7. https://doi.org/ 10.1016/j.gene.2014.02.051.

49. Stoehr $\mathrm{R}$, et al. Frequency of TERT promoter mutations in prostate Cancer. Pathobiology. 2015;82:53-7. https://doi.org/10.1159/000381903.

50. Hollenhorst PC, et al. Oncogenic ETS proteins mimic activated RAS/MAPK signaling in prostate cells. Genes Dev. 2011;25:2147-57. https://doi.org/10. 1101/gad.17546311.

51. Horn S, et al. TERT promoter mutations in familial and sporadic melanoma. Science. 2013;339:959-61. https://doi.org/10.1126/science.1230062.

52. Bell RJ, et al. Cancer. The transcription factor GABP selectively binds and activates the mutant TERT promoter in cancer. Science. 2015;348:1036-9. https://doi.org/10.1126/science.aab0015.

53. Stern JL, Theodorescu D, Vogelstein B, Papadopoulos N, Cech TR. Mutation of the TERT promoter, switch to active chromatin, and monoallelic TERT expression in multiple cancers. Genes Dev. 2015;29:2219-24. https://doi.org/ 10.1101/gad.269498.115.

54. Tergaonkar V. NFkappaB drives TERT promoter reactivation in cancer. Cell Cycle. 2016;15:156-7. https://doi.org/10.1080/15384101.2015.1118908.

55. Li Y, et al. Non-canonical NF-kappaB signalling and ETS1/2 cooperatively drive C250T mutant TERT promoter activation. Nat Cell Biol. 2015;17:1327-38. https://doi.org/10.1038/ncb3240.

56. Heidenreich $\mathrm{B}$, et al. Telomerase reverse transcriptase promoter mutations in primary cutaneous melanoma. Nat Commun. 2014;5:3401. https://doi.org/10 1038/ncomms4401.

57. Xie $\mathrm{H}$, et al. TERT promoter mutations and gene amplification: promoting TERT expression in Merkel cell carcinoma. Oncotarget. 2014;5:10048-57. https://doi.org/10.18632/oncotarget.2491.

58. Wu S, et al. Telomerase reverse transcriptase gene promoter mutations help discern the origin of urogenital tumors: a genomic and molecular study. Eur Urol. 2014:65:274-7. https://doi.org/10.1016/.eururo.2013.10.038.

59. Hosen I, et al. Mutations in TERT promoter and FGFR3 and telomere length in bladder cancer. Int J Cancer. 2015;137:1621-9. https://doi.org/10.1002/ijc.29526.

60. Melo M, da Rocha AG, Vinagre J, Sobrinho-Simoes M, Soares P. Coexistence of TERT promoter and BRAF mutations in papillary thyroid carcinoma: added value in patient prognosis? J Clin Oncol. 2015;33:667-8. https://doi. org/10.1200/JCO.2014.59.4614.

61. Griewank KG, et al. TERT promoter mutation status as an independent prognostic factor in cutaneous melanoma. J Natl Cancer Inst. 2014;106. https://doi.org/10.1093/jnci/dju246.

62. Borah S, et al. Cancer. TERT promoter mutations and telomerase reactivation in urothelial cancer. Science. 2015;347:1006-10. https://doi.org/10.1126/ science. 1260200.

63. Dong $\mathrm{R}$, Zheng $\mathrm{S}$, Dong K. TERT promoter mutation during development of hepatoblastoma to hepatocellular carcinoma. J Hepatol. 2015;62:497. https:// doi.org/10.1016/i.jhep.2014.10.045.

64. Heidenreich B, Rachakonda PS, Hemminki K, Kumar R. TERT promoter mutations in cancer development. Curr Opin Genet Dev. 2014;24:30-7. https://doi.org/10.1016/j.gde.2013.11.005.

65. Hurst CD, Platt FM, Knowles MA. Comprehensive mutation analysis of the TERT promoter in bladder cancer and detection of mutations in voided urine. Eur Urol. 2014;65:367-9. https://doi.org/10.1016/..eururo.2013.08.057.

66. Gunes C, Wezel F, Southgate J, Bolenz C. Implications of TERT promoter mutations and telomerase activity in urothelial carcinogenesis. Nat Rev Urol. 2018;15:386-93. https://doi.org/10.1038/s41585-018-0001-5.

67. Wang $K$, et al. TERT promoter mutations are associated with distant metastases in upper tract urothelial carcinomas and serve as urinary biomarkers detected by a sensitive castPCR. Oncotarget. 2014;5:12428-39. https://doi.org/10.18632/oncotarget.2660.

68. Liu R, Xing M. Diagnostic and prognostic TERT promoter mutations in thyroid fine-needle aspiration biopsy. Endocr Relat Cancer. 2014;21:825-30. https://doi.org/10.1530/ERC-14-0359. 
69. Vuong HG, Altibi AMA, Duong UNP, Hassell L. Prognostic implication of BRAF and TERT promoter mutation combination in papillary thyroid carcinoma-a meta-analysis. Clin Endocrinol. 2017;87:411-7. https://doi.org/ 10.1111/cen.13413.

70. Xing $M$, et al. BRAF V600E and TERT promoter mutations cooperatively identify the most aggressive papillary thyroid cancer with highest recurrence. J Clin Oncol. 2014;32:2718-26. https://doi.org/10.1200/JCO.2014. 55.5094.

71. Labussiere M, et al. Combined analysis of TERT, EGFR, and IDH status defines distinct prognostic glioblastoma classes. Neurology. 2014;83:1200-6. https:// doi.org/10.1212/WNL.0000000000000814.

72. Cancer Genome Atlas Research, N, et al. Comprehensive, Integrative Genomic Analysis of Diffuse Lower-Grade Gliomas. N Engl J Med. 2015;372: 2481-98. https://doi.org/10.1056/NEJMoa1402121.

73. Killela PJ, et al. Mutations in IDH1, IDH2, and in the TERT promoter define clinically distinct subgroups of adult malignant gliomas. Oncotarget. 2014;5: 1515-25. https://doi.org/10.18632/oncotarget.1765.

74. Heidenreich $B$, et al. TERT promoter mutations and telomere length in adult malignant gliomas and recurrences. Oncotarget. 2015;6:10617-33. https:// doi.org/10.18632/oncotarget.3329.

75. Nault JC, et al. Telomerase reverse transcriptase promoter mutation is an early somatic genetic alteration in the transformation of premalignant nodules in hepatocellular carcinoma on cirrhosis. Hepatology. 2014;60:198392. https://doi.org/10.1002/hep.27372.

76. Nagore $\mathrm{E}$, et al. TERT promoter mutations in melanoma survival. Int J Cancer. 2016;139:75-84. https://doi.org/10.1002/ijc.30042.

77. Hosen I, et al. TERT promoter mutations in clear cell renal cell carcinoma. Int J Cancer. 2015;136:2448-52. https://doi.org/10.1002/ijc.29279.

78. Niopoulos D, Satra M, Drakaki A, Poultsides GA, Tsezou A. Epigenetic regulation of hTERT promoter in hepatocellular carcinomas. Int J Oncol. 2009;34:391-9. https://doi.org/10.3892/ijo_00000162.

79. Lopatina NG, et al. Control mechanisms in the regulation of telomerase reverse transcriptase expression in differentiating human teratocarcinoma cells. Biochem Biophys Res Commun. 2003;306:650-9. https://doi.org/10. 1016/s0006-291x(03)01033-7.

80. Quante $M$, et al. Differential transcriptional regulation of human telomerase in a cellular model representing important genetic alterations in esophageal squamous carcinogenesis. Carcinogenesis. 2005;26:1879-89. https://doi.org/ 10.1093/carcin/bgi153.

81. Guilleret I, Benhattar J. Unusual distribution of DNA methylation within the hTERT CpG island in tissues and cell lines. Biochem Biophys Res Commun. 2004;325:1037-43. https://doi.org/10.1016/j.bbrc.2004.10.137.

82. Castelo-Branco P, et al. A cancer specific hypermethylation signature of the TERT promoter predicts biochemical relapse in prostate cancer: a retrospective cohort study. Oncotarget. 2016;7:57726-36. https://doi.org/10. 18632/oncotarget.10639.

83. Renaud S, et al. Dual role of DNA methylation inside and outside of CTCFbinding regions in the transcriptional regulation of the telomerase hTERT gene. Nucleic Acids Res. 2007;35:1245-56. https:/doi.org/10.1093/nar/gkl1125.

84. Castelo-Branco P, et al. Methylation of the TERT promoter and risk stratification of childhood brain tumours: an integrative genomic and molecular study. Lancet Oncol. 2013;14:534-42. https://doi.org/10.1016/ s1470-2045(13)70110-4

85. Renaud S, Loukinov D, Bosman FT, Lobanenkov V, Benhattar J. CTCF binds the proximal exonic region of hTERT and inhibits its transcription. Nucleic Acids Res. 2005;33:6850-60. https://doi.org/10.1093/nar/gki989.

86. Renaud S, Bosman FT, Benhattar J. Implication of the exon region in the regulation of the human telomerase reverse transcriptase gene promoter. Biochem Biophys Res Commun. 2003;300:47-54.

87. Oh S, Song Y, Yim J, Kim TK. The Wilms' tumor 1 tumor suppressor gene represses transcription of the human telomerase reverse transcriptase gene. J Biol Chem. 1999:274:37473-8.

88. Azouz A, et al. Epigenetic plasticity of hTERT gene promoter determines retinoid capacity to repress telomerase in maturation-resistant acute promyelocytic leukemia cells. Leukemia. 2010;24:613-22. https://doi.org/10. 1038/leu.2009.283.

89. Zinn RL, Pruitt K, Eguchi S, Baylin SB, Herman JG. hTERT is expressed in cancer cell lines despite promoter DNA methylation by preservation of unmethylated DNA and active chromatin around the transcription start site. Cancer Res. 2007:67:194-201. https://doi.org/10.1158/0008-5472. CAN-06-3396.
90. Berletch JB, et al. Epigenetic and genetic mechanisms contribute to telomerase inhibition by EGCG. J Cell Biochem. 2008;103:509-19. https://doi. org/10.1002/jcb.21417

91. Meeran SM, Patel SN, Tollefsbol TO. Sulforaphane causes epigenetic repression of hTERT expression in human breast cancer cell lines. PLoS One. 2010;5:e11457. https://doi.org/10.1371/journal.pone.0011457.

92. Li Y, Liu L, Andrews LG, Tollefsbol TO. Genistein depletes telomerase activity through cross-talk between genetic and epigenetic mechanisms. Int J Cancer. 2009;125:286-96. https://doi.org/10.1002/ijc.24398.

93. Meeran SM, Patel SN, Chan TH, Tollefsbol TO. A novel prodrug of epigallocatechin-3-gallate: differential epigenetic hTERT repression in human breast cancer cells. Cancer Prev Res (Phila). 2011:4:1243-54. https://doi.org/ 10.1158/1940-6207.CAPR-11-0009.

94. Cong YS, Bacchetti S. Histone deacetylation is involved in the transcriptional repression of hTERT in normal human cells. J Biol Chem. 2000;275:35665-8. https://doi.org/10.1074/jbc.C000637200.

95. Takakura $\mathrm{M}$, et al. Telomerase activation by histone deacetylase inhibitor in normal cells. Nucleic Acids Res. 2001;29:3006-11.

96. Wang S, Hu C, Zhu J. Transcriptional silencing of a novel hTERT reporter locus during in vitro differentiation of mouse embryonic stem cells. Mol Biol Cell. 2007:18:669-77. https://doi.org/10.1091/mbc.e06-09-0840.

97. Kretzner $L$, et al. Combining histone deacetylase inhibitor vorinostat with aurora kinase inhibitors enhances lymphoma cell killing with repression of c-Myc, hTERT, and microRNA levels. Cancer Res. 2011;71:3912-20. https:// doi.org/10.1158/0008-5472.CAN-10-2259.

98. Atkinson SP, Hoare SF, Glasspool RM, Keith WN. Lack of telomerase gene expression in alternative lengthening of telomere cells is associated with chromatin remodeling of the hTR and hTERT gene promoters. Cancer Res. 2005;65:7585-90. https://doi.org/10.1158/0008-5472.CAN-05-1715.

99. Liu C, et al. The telomerase reverse transcriptase (hTERT) gene is a direct target of the histone methyltransferase SMYD3. Cancer Res. 2007:67:262631. https://doi.org/10.1158/0008-5472.CAN-06-4126.

100. Man K, Zhang B, Chen J, Cheng ASL, Ko BCB. Depletion of Sirtuin 1 (SIRT1) leads to epigenetic modifications of telomerase (TERT) gene in hepatocellular carcinoma cells. PLoS One. 2014;9:e84931. https://doi.org/10.1371/journal.pone.0084931.

101. Mao B, et al. Sirt1 deacetylates c-Myc and promotes c-Myc/max association. Int J Biochem Cell Biol. 2011;43:1573-81. https://doi.org/10.1016/j.biocel. 2011.07.006.

102. Choi JH, et al. TSA-induced DNMT1 down-regulation represses hTERT expression via recruiting CTCF into demethylated core promoter region of hTERT in HCT116. Biochem Biophys Res Commun. 2010;391:449-54. https:// doi.org/10.1016/j.bbrc.2009.11.078.

103. Yi X, et al. An alternate splicing variant of the human telomerase catalytic subunit inhibits telomerase activity. Neoplasia. 2000;2:433-40. https://doi. org/10.1038/sj.neo.7900113.

104. Colgin LM, et al. The hTERTa splice variant is a dominant negative inhibitor of telomerase activity. Neoplasia. 2000;2:426-32. https://doi.org/10.1038/sj. neo.7900112.

105. Listerman I, Sun J, Gazzaniga FS, Lukas JL, Blackburn EH. The major reverse transcriptase-incompetent splice variant of the human telomerase protein inhibits telomerase activity but protects from apoptosis. Cancer Res. 2013; 73:2817-28. https://doi.org/10.1158/0008-5472.CAN-12-3082.

106. Nicholson $P$, et al. Nonsense-mediated mRNA decay in human cells: mechanistic insights, functions beyond quality control and the double-life of NMD factors. Cell Mol Life Sci. 2010;67:677-700. https://doi.org/10.1007/ s00018-009-0177-1.

107. Wong MS, et al. Regulation of telomerase alternative splicing: a target for chemotherapy. Cell Rep. 2013;3:1028-35. https://doi.org/10.1016/j.celrep. 2013.03.011.

108. Leem SH, et al. The human telomerase gene: complete genomic sequence and analysis of tandem repeat polymorphisms in intronic regions. Oncogene. 2002;21:769-77. https://doi.org/10.1038/sj.onc.1205122.

109. Cerezo A, Kalthoff H, Schuermann M, Schafer B, Boukamp P. Dual regulation of telomerase activity through c-Myc-dependent inhibition and alternative splicing of hTERT. J Cell Sci. 2002;115:1305-12.

110. Ludlow AT, et al. NOVA1 regulates hTERT splicing and cell growth in nonsmall cell lung cancer. Nat Commun. 2018;9:3112. https://doi.org/10.1038/ s41467-018-05582-x.

111. Villate $\mathrm{O}$, et al. Nova1 is a master regulator of alternative splicing in pancreatic beta cells. Nucleic Acids Res. 2014;42:11818-30. https://doi.org/ 10.1093/nar/gku861. 
112. Drummond MW, Balabanov S, Holyoake TL, Brummendorf TH. Concise review: telomere biology in normal and leukemic hematopoietic stem cells. Stem Cells. 2007;25:1853-61. https://doi.org/10.1634/stemcells.2007-0057.

113. Ulaner GA, et al. Regulation of telomerase by alternate splicing of human telomerase reverse transcriptase (hTERT) in normal and neoplastic ovary, endometrium and myometrium. Int J Cancer. 2000;85:330-5.

114. Ulaner GA, Hu JF, Vu TH, Giudice LC, Hoffman AR. Telomerase activity in human development is regulated by human telomerase reverse transcriptase (hTERT) transcription and by alternate splicing of hTERT transcripts. Cancer Res. 1998;58:4168-72.

115. Xu D, Gruber A, Bjorkholm M, Peterson C, Pisa P. Suppression of telomerase reverse transcriptase (hTERT) expression in differentiated $\mathrm{HL}-60$ cells: regulatory mechanisms. Br J Cancer. 1999;80:1156-61. https://doi.org/10. 1038/sj.bjc.6690480.

116. Yatabe $\mathrm{N}$, et al. HIF-1-mediated activation of telomerase in cervical cancer cells. Oncogene. 2004;23:3708-15. https://doi.org/10.1038/sj.onc.1207460.

117. Nishi $\mathrm{H}$, et al. Hypoxia-inducible factor 1 mediates upregulation of telomerase (hTERT). Mol Cell Biol. 2004;24:6076-83. https://doi.org/10.1128/ MCB.24.13.6076-6083.2004

118. Anderson CJ, Hoare SF, Ashcroft M, Bilsland AE, Keith WN. Hypoxic regulation of telomerase gene expression by transcriptional and post-transcriptional mechanisms. Oncogene. 2006;25:61-9. https://doi.org/10.1038/sj.onc.1209011.

119. Radan L, et al. Microenvironmental regulation of telomerase isoforms in human embryonic stem cells. Stem Cells Dev. 2014;23:2046-66. https://doi. org/10.1089/scd.2013.0373

120. Zhdanov DD, et al. Alternative splicing of telomerase catalytic subunit hTERT generated by apoptotic endonuclease EndoG induces human CD4(+) T cell death. Eur J Cell Biol. 2017;96:653-64. https://doi.org/10.1016/j.ejcb.2017.08.004.

121. Mitomo S, et al. Downregulation of miR-138 is associated with overexpression of human telomerase reverse transcriptase protein in human anaplastic thyroid carcinoma cell lines. Cancer Sci. 2008;99:280-6. https:// doi.org/10.1111/j.1349-7006.2007.00666.x.

122. Qin YZ, et al. Screening and preliminary validation of miRNAs with the regulation of hTERT in colorectal cancer. Oncol Rep. 2015;33:2728-36. https://doi.org/10.3892/or.2015.3892.

123. Li M, et al. microRNA2993p inhibits laryngeal cancer cell growth by targeting human telomerase reverse transcriptase mRNA. Mol Med Rep. 2015;11:4645-9. https://doi.org/10.3892/mmr.2015.3287.

124. Li J, Lei H, Xu Y, Tao ZZ. miR-512-5p suppresses tumor growth by targeting hTERT in telomerase positive head and neck squamous cell carcinoma in vitro and in vivo. PLoS One. 2015;10:e0135265. https://doi.org/10.1371/ journal.pone.0135265.

125. Li Z, Liu YH, Diao HY, Ma J, Yao YL. MiR-661 inhibits glioma cell proliferation, migration and invasion by targeting hTERT. Biochem Biophys Res Commun. 2015:468:870-6. https://doi.org/10.1016/j.bbrc.2015.11.046.

126. Zhang $\mathrm{D}$, et al. miR-1182 attenuates gastric cancer proliferation and metastasis by targeting the open reading frame of hTERT. Cancer Lett. 2015; 360:151-9. https://doi.org/10.1016/j.canlet.2015.01.044.

127. Zhou J, Dai W, Song J. miR-1182 inhibits growth and mediates the chemosensitivity of bladder cancer by targeting hTERT. Biochem Biophys Res Commun. 2016;470:445-52. https://doi.org/10.1016/j.bbrc.2016.01.014.

128. Chen L, et al. miR-1207-5p and miR-1266 suppress gastric cancer growth and invasion by targeting telomerase reverse transcriptase. Cell Death Dis. 2014;5:e1034. https://doi.org/10.1038/cddis.2013.553.

129. Zhao Q, Zhai YX, Liu HQ, Shi YA, Li XB. MicroRNA-491-5p suppresses cervical cancer cell growth by targeting hTERT. Oncol Rep. 2015;34:979-86. https:// doi.org/10.3892/or.2015.4013

130. Hrdlickova R, Nehyba J, Bargmann W, Bose HR Jr. Multiple tumor suppressor microRNAs regulate telomerase and TCF7, an important transcriptional regulator of the Wnt pathway. PLoS One. 2014;9:e86990. https://doi.org/10. 1371/journal.pone.0086990.

131. Bai L, Wang H, Wang AH, Zhang LY, Bai J. MicroRNA-532 and microRNA3064 inhibit cell proliferation and invasion by acting as direct regulators of human telomerase reverse transcriptase in ovarian cancer. PLoS One. 2017; 12:e0173912. https://doi.org/10.1371/journal.pone.0173912.

132. Kasiappan $\mathrm{R}$, et al. 1,25-Dihydroxyvitamin D3 suppresses telomerase expression and human cancer growth through microRNA-498. J Biol Chem. 2012;287:41297-309. https://doi.org/10.1074/jbc.M112.407189.

133. Xu X, et al. miR-34a induces cellular senescence via modulation of telomerase activity in human hepatocellular carcinoma by targeting FoxM1/c-Myc pathway. Oncotarget. 2015;6:3988-4004. https://doi.org/10.18632/oncotarget.2905.
134. Yan T, et al. HoxC5 and miR-615-3p target newly evolved genomic regions to repress hTERT and inhibit tumorigenesis. Nat Commun. 2018;9:100. https://doi.org/10.1038/s41467-017-02601-1.

135. Song G, et al. miR-346 and miR-138 competitively regulate hTERT in GRSF1and AGO2-dependent manners, respectively. Sci Rep. 2015;5:15793. https:// doi.org/10.1038/srep15793.

136. Ohira T, et al. miR-19b regulates hTERT mRNA expression through targeting PITX1 mRNA in melanoma cells. Sci Rep. 2015;5:8201. https://doi.org/10. 1038/srep08201.

137. Farhana L, Dawson Ml, Fontana JA. Down regulation of miR-202 modulates Mxd1 and Sin3A repressor complexes to induce apoptosis of pancreatic cancer cells. Cancer Biol Ther. 2015;16:115-24. https://doi.org/10.4161/ 15384047.2014.987070.

138. Feng $\mathrm{YH}$, et al. Deregulated expression of sprouty 2 and microRNA-21 in human colon cancer: correlation with the clinical stage of the disease. Cancer Biol Ther. 2011;11:111-21

139. Yang $Y$, Yang JJ, Tao $H$, Jin WS. MicroRNA-21 controls hTERT via PTEN in human colorectal cancer cell proliferation. J Physiol Biochem. 2015;71:59-68. https://doi.org/10.1007/s13105-015-0380-5.

140. Ulitsky I, Bartel DP. lincRNAs: genomics, evolution, and mechanisms. Cell. 2013:154:26-46. https://doi.org/10.1016/j.cell.2013.06.020

141. Batista PJ, Chang HY. Long noncoding RNAs: cellular address codes in development and disease. Cell. 2013;152:1298-307. https://doi.org/10.1016/j. cell.2013.02.012.

142. Malhotra S, Freeberg MA, Winans SJ, Taylor J, Beemon KL. A novel long non-coding RNA in the hTERT promoter region regulates hTERT expression. Noncoding RNA. 2017;4. https://doi.org/10.3390/ncrna4010001.

143. Aiello A, et al. MALAT1 and HOTAIR long non-coding RNAs play opposite role in estrogen-mediated transcriptional regulation in prostate Cancer cells. Sci Rep. 2016;6:38414. https://doi.org/10.1038/srep38414.

144. Hu Z, et al. Beta-Elemene inhibits the proliferation of esophageal squamous cell carcinoma by regulating long noncoding RNA-mediated inhibition of hTERT expression. Anti-Cancer Drugs. 2015;26:531-9. https://doi.org/10.1097/ CAD.0000000000000216.

145. Lu MH, et al. Long noncoding RNA BC032469, a novel competing endogenous RNA, upregulates hTERT expression by sponging miR-1207-5p and promotes proliferation in gastric cancer. Oncogene. 2016;35:3524-34. https://doi.org/10.1038/onc.2015.413.

146. Pu H, et al. CUDR promotes liver cancer stem cell growth through upregulating TERT and C-Myc. Oncotarget. 2015;6:40775-98. https://doi.org/ 10.18632/oncotarget.5805

147. Redon S, Reichenbach $\mathrm{P}$, Lingner J. The non-coding RNA TERRA is a natural ligand and direct inhibitor of human telomerase. Nucleic Acids Res. 2010;38: 5797-806. https://doi.org/10.1093/nar/gkq296.

148. Zhang XL, Xu LL, Wang F. Hsa_circ_0020397 regulates colorectal cancer cell viability, apoptosis and invasion by promoting the expression of the miR138 targets TERT and PD-L1. Cell Biol Int. 2017;41:1056-64. https://doi.org/ 10.1002/cbin.10826.

149. Kang SS, Kwon T, Kwon DY, Do SI. Akt protein kinase enhances human telomerase activity through phosphorylation of telomerase reverse transcriptase subunit. J Biol Chem. 1999;274:13085-90.

150. Chung J, Khadka P, Chung IK. Nuclear import of hTERT requires a bipartite nuclear localization signal and Akt-mediated phosphorylation. J Cell Sci. 2012;125:2684-97. https://doi.org/10.1242/jcs.099267.

151. Jeong SA, et al. Akt-mediated phosphorylation increases the binding affinity of hTERT for importin alpha to promote nuclear translocation. J Cell Sci. 2015;128:2951. https://doi.org/10.1242/jcs.176453.

152. Chang JT, et al. hTERT phosphorylation by PKC is essential for telomerase holoprotein integrity and enzyme activity in head neck cancer cells. $\mathrm{Br} J$ Cancer. 2006;94:870-8. https://doi.org/10.1038/sj.bjc.6603008.

153. Li H, Zhao L, Yang Z, Funder JW, Liu JP. Telomerase is controlled by protein kinase Calpha in human breast cancer cells. J Biol Chem. 1998; 273:33436-42

154. Haendeler J, Hoffmann J, Brandes RP, Zeiher AM, Dimmeler S. Hydrogen peroxide triggers nuclear export of telomerase reverse transcriptase via Src kinase family-dependent phosphorylation of tyrosine 707. Mol Cell Biol. 2003;23:4598-610. https://doi.org/10.1128/mcb.23.13.4598-4610.2003.

155. Buchner N, Zschauer TC, Lukosz M, Altschmied J, Haendeler J. Downregulation of mitochondrial telomerase reverse transcriptase induced by $\mathrm{H} 2 \mathrm{O} 2$ is Src kinase dependent. Exp Gerontol. 2010;45:558-62. https://doi. org/10.1016/j.exger.2010.03.003. 
156. Jakob S, et al. Nuclear protein tyrosine phosphatase Shp-2 is one important negative regulator of nuclear export of telomerase reverse transcriptase. J Biol Chem. 2008;283:33155-61. https://doi.org/10.1074/jbc.M805138200.

157. Kharbanda S, et al. Regulation of the hTERT telomerase catalytic subunit by the c-Abl tyrosine kinase. Curr Biol. 2000;10:568-75.

158. Liu K, Hodes RJ, Weng N. Cutting edge: telomerase activation in human T lymphocytes does not require increase in telomerase reverse transcriptase (hTERT) protein but is associated with hTERT phosphorylation and nuclear translocation. J Immunol. 2001;166:4826-30. https://doi.org/10.4049/ jimmunol.166.8.4826.

159. Mertins $\mathrm{P}$, et al. Proteogenomics connects somatic mutations to signalling in breast cancer. Nature. 2016;534:55-62. https://doi.org/10.1038/nature18003.

160. Tao WA, et al. Quantitative phosphoproteome analysis using a dendrimer conjugation chemistry and tandem mass spectrometry. Nat Methods. 2005; 2:591-8. https://doi.org/10.1038/nmeth776.

161. Kim JH, et al. Ubiquitin ligase MKRN1 modulates telomere length homeostasis through a proteolysis of hTERT. Genes Dev. 2005;19:776-81. https://doi.org/10.1101/gad.1289405.

162. Oh $\mathrm{W}$, et al. $\mathrm{Hdm} 2$ negatively regulates telomerase activity by functioning as an E3 ligase of hTERT. Oncogene. 2010;29:4101-12. https://doi.org/10. 1038/onc.2010.160.

163. Lee JH, Khadka P, Baek SH, Chung IK. CHIP promotes human telomerase reverse transcriptase degradation and negatively regulates telomerase activity. J Biol Chem. 2010;285:42033-45. https://doi.org/10.1074/jbc.M110. 149831.

164. Hao ZM, et al. Intensive inhibition of hTERT expression by a ribozyme induces rapid apoptosis of cancer cells through a telomere lengthindependent pathway. Cancer Biol Ther. 2005;4:1098-103.

165. Sachsinger J, et al. Telomerase inhibition in RenCa, a murine tumor cell line with short telomeres, by overexpression of a dominant negative mTERT mutant, reveals fundamental differences in telomerase regulation between human and murine cells. Cancer Res. 2001;61:5580-6.

166. Adotevi O, et al. Immunogenic HLA-B*0702-restricted epitopes derived from human telomerase reverse transcriptase that elicit antitumor cytotoxic T-cell responses. Clin Cancer Res. 2006;12:3158-67. https://doi.org/10.1158/10780432.CCR-05-2647.

167. Bernardeau K, et al. A simple competitive assay to determine peptide affinity for HLA class II molecules: a useful tool for epitope prediction. J Immunol Methods. 2011;371:97-105. https://doi.org/10.1016/j.jim.2011.06.018.

168. Jacob D, et al. Suppressing orthotopic pancreatic tumor growth with a fiber-modified adenovector expressing the TRAIL gene from the human telomerase reverse transcriptase promoter. Clin Cancer Res. 2004;10:3535-41. https:/doi.org/10.1158/1078-0432.CCR-03-0512

Ready to submit your research? Choose BMC and benefit from:

- fast, convenient online submission

- thorough peer review by experienced researchers in your field

- rapid publication on acceptance

- support for research data, including large and complex data types

- gold Open Access which fosters wider collaboration and increased citations

- maximum visibility for your research: over $100 \mathrm{M}$ website views per year

At $\mathrm{BMC}$, research is always in progress.

Learn more biomedcentral.com/submissions 